\title{
An unusual presentation of alveolar haemorrhage
}

\author{
*Jesús M Román-Vélez ${ }^{a}$, Ruth N Martínez-Camacho ${ }^{b}$, Diógenes Alayón-Laguer \\ Ricardo Fernández-González ${ }^{\mathrm{a}}$, Raul Reyes-Sosa ${ }^{\mathrm{a}}$, Glorimar Santos-Llanosa, \\ Miguel Colón-Pérez ${ }^{a}$, Dimas Ferrer ${ }^{a}$
}

\author{
a Pulmonary Training Program, San Juan City Hospital, Puerto Rico \\ b Internal Medicine Program, San Juan City Hospital, Puerto Rico
}

Received 1st March 2009; revised version received 2nd April 2009; accepted 2nd June 2009; online 15 th September 2009

\begin{abstract}
Summary
We report the case of a female patient with an atypical case of alveolar haemorrhage secondary to disseminated strongyloidiasis. Although uncommon, clinicians should consider the diagnosis of pneumonia by disseminated strongyloidiasis in patients with endemic exposure to Strongyloides stercoralis who present with symptoms of cough, wheezing, and dyspnoea. Primary care physicians should strongly consider screening for strongyloidiasis in patients from endemic areas prior to considering the use of steroids or any other immunosuppressants. The best screening test would be serological testing.

(C) 2009 General Practice Airways Group. All rights reserved.

JM Román-Vélez et al. Prim Care Resp J 2009; 18(4): 337-339

doi:10.4104/pcrj.2009.00049
\end{abstract}

Keywords Strongyloides stercoralis, pneumonia, disseminated strongyloidiasis, alveolar haemorrhage, immunocompetent

\section{Introduction}

Disseminated strongyloidiasis is a fatal and severe infectious process which usually presents in immunocompromised patients with respiratory tract symptoms. It is rarely described in immunocompetent patients - who are usually asymptomatic or present with mild gastrointestinal or dermatological symptoms. We report the case of a female patient with an atypical case of alveolar haemorrhage secondary to disseminated strongyloidiasis.

\section{Case report}

A 54 year-old female born in the Dominican Republic, who had emigrated to Puerto Rico at the age of 34, presented to the emergency room complaining of progressive dyspnoea, wheezing, and a dry persistent cough of two weeks' duration. Past medical history included diabetes mellitus type II and hypertension. Social habits included a 36 pack-year smoking history and occasional use of alcohol. She was a selfemployed housekeeper. There was no relevant travel history. One week prior to admission she had been evaluated by her primary care physician and treated with bronchodilators and a single dose of $60 \mathrm{mg}$ of methylprednisolone intravenously. She denied any skin rashes, fever, chills, nausea, vomiting, abdominal pain, diarrhoea, weight loss, constipation, or any sick contacts. On physical examination the patient was alert, with proper cognitive skills, but with mild respiratory difficulty. Vital signs included a pulse of 116 beats per minute, blood pressure of $145 / 96 \mathrm{mmHg}$, temperature $36.6^{\circ} \mathrm{C}$, and respiratory rate of 24 per minute with oxygen saturation $90 \%$ in air. Auscultation of the lung fields revealed bilateral ronchi, prolonged expiratory phase and diffuse expiratory wheezes. Abdominal examination was unremarkable. The skin did not show evidence of lacerations, urticaria, petechia or purpura.

Laboratory tests showed a raised white blood cell count of $20,400 / \mu \mathrm{L}$ with a differential of $91.8 \%$ neutrophils, $4.6 \%$ lymphocytes, $3.2 \%$ monocytes and $0.1 \%$ eosinophils. Platelet count was $330,000 / \mu \mathrm{L}$, haemoglobin $15.1 \mathrm{~g} / \mathrm{dl}$ and haematocrit $40 \%$. Arterial blood gases showed an oxygen saturation of $93.1 \%$. Her alveolar-arterial gradient was calculated at 42. Electrolytes were within normal limits.

Chest X-ray done on the day of admission showed bilateral diffuse interstitial infiltrates (see Figure 1). A CT-scan

\footnotetext{
* Corresponding author: Dr Jesús M Román-Vélez, Pulmonary Training Program, San Juan City Hospital, PMB-463 Training Program, PMB-463 PO Box 70344, San Juan 00936-8344, Puerto Rico. Tel: 787-765-3692 E-mail: manuelroman07@gmail.com
} 
Figure 1. Chest $\mathrm{X}$-ray prior to admission showing bilateral diffuse interstitial infiltrates.

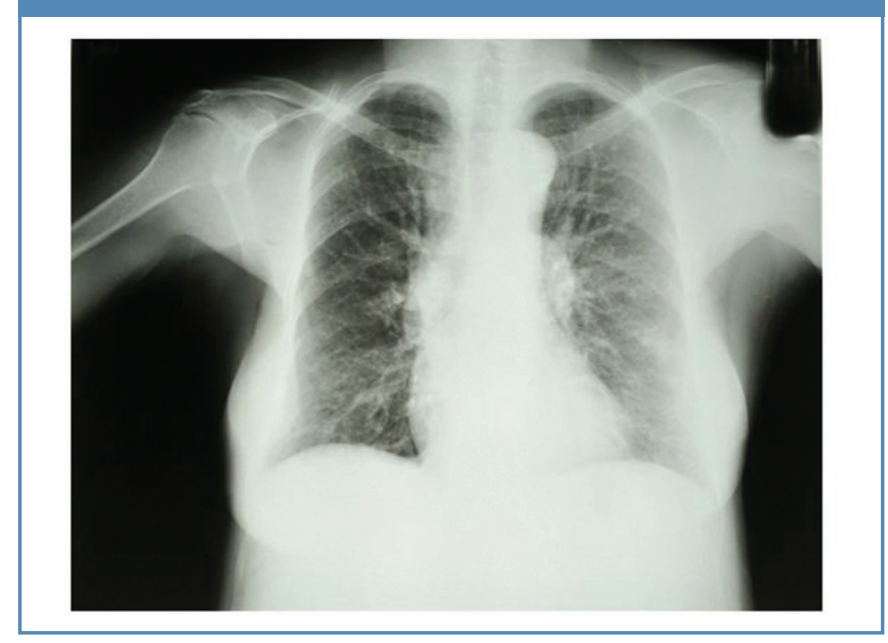

of the chest demostrated bilateral hilar and mediastinal lymphadenopathy with ground glass opacities.

The patient's immune status was queried; lab work and pertinent history was obtained. Chronic use of steroids prior to admission was denied. Glycosylated haemoglobin was within normal limits. Immunoglobulin levels, complement levels, CD 4/CD 8 counts and HIV test were unremarkable. HTLV-1 infection was another diagnostic possibility, but this was less likely since the patient did not present with the necessary risk factors, immunoglobulin levels (including lgE) were normal, and the incidence of HTLV-1 in Puerto Rico and Dominican Republic is low compared to other Caribbean countries such as Haiti and Jamaica.'

The patient was treated with bronchodilators, oxygen supplements, intravenous steroids, and antibiotic therapy for pneumonia with bronchospasm. During the first 24 hours of admission she developed dyspnoea at rest and a productive cough with yellowish blood-tinged sputum. However, over the next 24 hours the dyspnoea worsened and she eventually developed respiratory failure requiring endotracheal intubation.

Fibreoptic bronchoscopy was performed showing alveolar haemorrhage for which high dose steroids were started in view of a suspected vasculitis. Bronchoalveolar lavage specimens were obtained from both lung bases and cytology revealed many larvae consistent with Strongyloides stercoralis (see Figure 2). On receiving this report steroids were withdrawn and the patient was started on Ivermectin and Albendazole. 48 hours later she developed multiple organ failure and died.

\section{Discussion}

Strongyloides stercoralis is a nematode which completes its life cycle within humans, setting up an autoinfection that can persist for decades after initial exposure. ${ }^{2}$ Strongyloides
Figure 2. Broncho-alveolar lavage specimen showing larvae consistent with Strongyloides stercoralis.

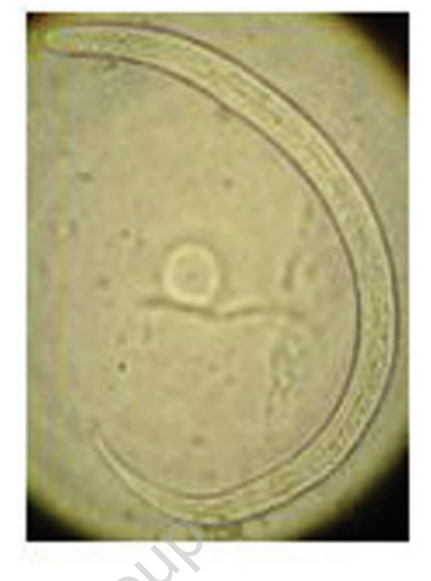

infection occurs via the skin from soil contaminated with the infective filariform larvae. On entering the skin, the larvae enter the lymphatic and venous systems, then the right side of the heart and the lungs. After penetrating into the alveolar spaces, larvae migrate up to the trachea and the glottis. Finally the larvae is swallowed and reaches the duodenum and proximal jejunum. ${ }^{2}$ At the upper gastrointestinal tract they are able to multiply with up to 40 eggs per day evolving into rhabditiform larvae. Some non-infective larvae may metamorphose into infective forms within the gut (rhabditiform to filariform larvae), invade the gastrointestinal wall or peri-anal skin, and establish an endogenous hyperinfection cycle. ${ }^{3,4}$

Immunocompetent hosts who are chronically infected are mainly asymptomatic, and the only clinical manifestation may be an eosinophilia over $10 \%$. Lack of an eosinophilic reaction indicates a poor immune response and is associated with a high mortality rate, ${ }^{3}$ as was seen in our patient.

Immunocompromised hosts can suffer from disseminated strongyloidiasis. Reported cases include HIV positive or AIDS patients, solid organ transplant recipients, patients with chronic lung disease, and patients with depressed cell mediated immunity due to chronic use of corticosteroids. $2,3,5$ In these cases the eosinophilia is absent and the reported symptoms are gastrointestinal in origin. Complications include gastrointestinal haemorrhage, peritonitis, and enteric gram negative bacterial sepsis due to translocation. ${ }^{5}$

Pneumonia is considered to be a manifestation of disseminated strongyloidiasis in an immunocompromised host. It presents as cough, haemoptysis and respiratory failure, and chest X-ray is consistent with a pattern of bilateral interstitial alveolar infiltrates. However, to our knowledge, this is the first case report that describes disseminated strongyloidiasis and alveolar haemorrhage in an 


\section{Learning Points:}

- Disseminated strongyloidiasis can cause asthma-like symptoms and should be suspected in patients who have been exposed in endemic areas.

- In patients with acute bilateral infiltrates associated with respiratory symptoms, early bronchoscopy increases the yield of an accurate diagnosis.

- Alveolar haemorrhage is a manifestation of disseminated strongyloidiasis.

- Patient with disseminated strongyloidiasis should be treated with Ivermectin, Albendazole, or Thiabendazole.

immunocompetent patient.

To make the diagnosis of pneumonia by strongyloidiasis requires very strong clinical suspicion. As in our patient, clinical clues include endemic exposure and worsening pulmonary signs and symptoms - which may have been the natural progression of this hyperinfection or may have been worsened by the administration of corticosteroids. Despite early diagnosis and therapy, disseminated strongyloidiasis still carries a mortality of $70 \%$. As shown in a review of 27 cases over a 5-year period, it occurs most commonly in immunocompromised patients and has a mortality rate of 70 $86 \% .{ }^{6}$ In a recent retrospective study on the clinical course and outcome of disseminated strongyloidiasis from Hong Kong, seven cases were identified; most patients were immunosuppresed and $71 \%$ of patients with lung involvement died despite aggressive supportive therapy.)

Other than originating from an endemic area for Strongyloides stercoralis, our patient had no other identifiable risk factor for her hyperinfection. She had no previous signs or symptoms consistent with chronic strongyloidiasis.
Furthermore, the clinical diagnosis was challenging since the laboratory tests and physical examination were not suggestive of this diagnosis; disseminated strongyloidiasis is rarely found in an immunocompetent patient, and to make the diagnosis requires very strong suspicion in order to prevent the late and often fatal complications.

\section{Conflict of interest declaration}

No conflicts of interest.

\section{Consent to publish}

Full consent was obtained from the patient's family prior to the publication of this case report.

\section{References}

1. Carneiro-Proietti A, Catalan-Soares B, et al. HTLV in the Americas: challenges and perspectives. Pan Am J Public Health 2006;19(1):44-53.

2. Chu E, Whitlock WL, Dietrich RA. Pulmonary hyperinfection syndrome with Strongyloides stercoralis. Chest 1990;97(6):1475-7 http://dx.doi.org/ 10.1378/chest.97.6.1475

3. Lessnau KD, Can S, Talavera W. Disseminated Strongyloides stercoralis in human immunodeficiency virus-infected patients. Chest 1993;104(1):119-22.

4. Chitkara RK, Krishna G. Parasitic Pulmonary Eosinophilia. Semin Respir Crit Care Med 2006;27(2):171-83. http://dx.doi.org/10.1055/s-2006-939520

5. Newberry AM, Williams DN, Stauffer WM, Boulware BR, Hendel-Paterson BR, Walker P. Strongyloides hyperinfection presenting as acute respiratory failure and gram negative sepsis. Chest 2005;128(5):3681-4. http://dx.doi.org/ 10.1378/chest.128.5.3681

6. Adedayo O, Grell G, Bellot P. Hyperinfective Strongyloidiasis in the medical ward: review of 27 cases in 5 years. South Med J 2002;95(7):711-16.

7. Lam CS, Tong MK, Chang KM, Siu YT. Disseminated strongyloidiasis: a retrospective study of clinical course and outcome. Eur J Clin Microbiol Infect Dis 2006;25(1):14-18. http://dx.doi.org/10.1007/s10096-005-0070-2

8. Asdamongkol N, Pornsuriyasak P, Sungkanuparph S. Risks factors for Strongyloidiasis hyperinfection and clinical outcomes. Southeast Asian J Trop Med Public Health 2006;37(5):875-84.

9. Fardet L, Généreau T, Poirot JL, Guidet B, Kettaneh A, Cabane J. Severe strongyloidiasis in corticosteroid-treated patients: case series and literature review. J Infect 2007;54(1):18-27.

\section{Editors' tribute to PCRJ reviewers, 2009}

On behalf of the Editors and publishers of the Primary Care Respiratory Journal, I would like to thank all those individuals who kindly donated their valuable time to assist us in refereeing manuscripts submitted to the journal. This work, undertaken despite extremely busy schedules, by experts in their field, is fundamental to our success in publishing high quality, peer-reviewed material. Without your help, we simply could not function efficiently - so Thank You all.

Dr Mark L Levy

Editor-in-Chief Primary Care Respiratory Journal 